Wiedemann, D., Lüdtke, T., Palatinus, L., Willinger, E., Willinger, M. G., Mühlbauer, M. J., \& Lerch, M.

\title{
At the Gates: The Tantalum-Rich Phase Hf3Ta2O11 and its Commensurately Modulated Structure
}

Journal article | Accepted manuscript (Postprint)

This version is available at https://doi.org/10.14279/depositonce-7673

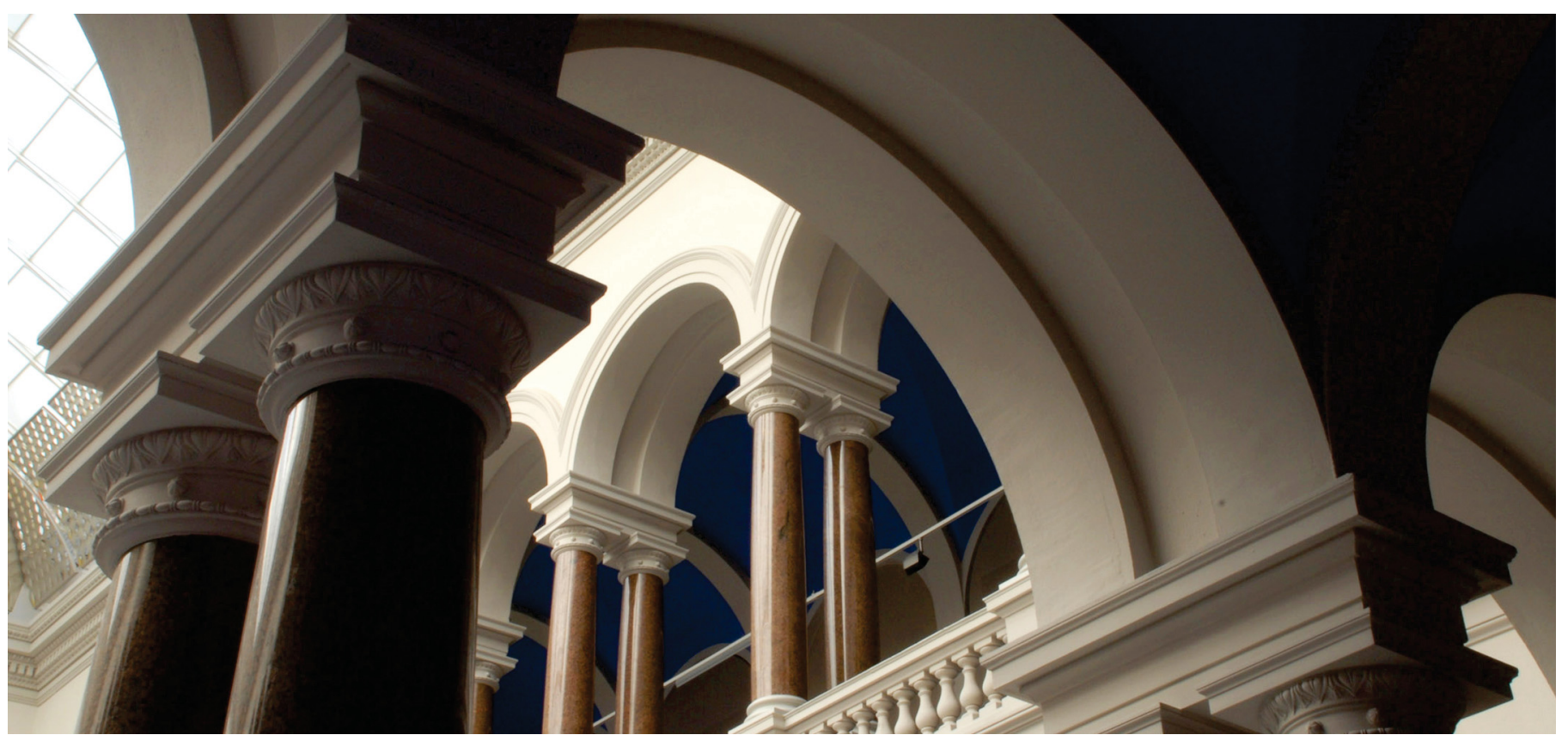

This document is the Accepted Manuscript version of a Published Work that appeared in final form in Inorganic Chemistry, copyright (c) American Chemical Society after peer review and technical editing by the publisher. To access the final edited and published work see https://doi.org/10.1021/acs.inorgchem.8b02642

Wiedemann, D., Lüdtke, T., Palatinus, L., Willinger, E., Willinger, M. G., Mühlbauer, M. J., \& Lerch, M. (2018). At the Gates: The Tantalum-Rich Phase Hf3Ta2O11 and its Commensurately Modulated Structure. Inorganic Chemistry, 57(22), 14435-14442. https://doi.org/10.1021/acs.inorgchem.8b02642 


\title{
At the Gates: The Tantalum-Rich Phase $\mathrm{Hf}_{3} \mathrm{Ta}_{2} \mathrm{O}_{11}$
}

\section{and its Commensurately Modulated Structure}

Dennis Wiedemann *广, Tobias Lüdtke ${ }^{\dagger}$, Lukáš Palatinus ${ }^{\dagger}$, Elena Willinger ${ }^{\S}$, Marc G. Willinger ${ }^{\S}$, Martin J. Mühlbauer", Martin Lerch ${ }^{\dagger}$

\author{
†Institut für Chemie, Technische Universität Berlin, 10623 Berlin, Germany \\ Institute of Physics, Czech Academy of Sciences, 18221 Prague 8, Czech Republic \\ $\S$ Abteilung Anorganische Chemie, Fritz-Haber-Institut, 14195 Berlin, Germany \\ "Heinz Maier-Leibnitz Zentrum (MLZ), Technische Universität München, 85747 Garching, \\ Germany
}

ABSTRACT. Generic mixtures in the system $(\mathrm{Zr}, \mathrm{Hf}) \mathrm{O}_{2}-(\mathrm{Nb}, \mathrm{Ta})_{2} \mathrm{O}_{5}$ are employed as tunable gate materials for field-effect transistors. Whereas production processes and target compositions are well-defined, resulting crystal structures are vastly unexplored. In this study, we summarize the sparse reported findings and present the new phase $\mathrm{Hf}_{3} \mathrm{Ta}_{2} \mathrm{O}_{11}$ as synthesized via a sol-gel route. Its commensurately modulated structure represents the hitherto unknown, metal(V)-richest member of the family $(\mathrm{Zr}, \mathrm{Hf})_{x}(\mathrm{Nb}, \mathrm{Ta})_{2} \mathrm{O}_{2 x+5}$. Based on electron, neutron, and $\mathrm{X}$-ray diffraction, the crystal structure is described within modern superspace $\left[\mathrm{Hf}_{1.2} \mathrm{Ta}_{0.8} \mathrm{O}_{4.4}, Z=2, a=4.7834(13)\right.$, $b=5.1782(17), c=5.064(3) \AA, \boldsymbol{q}=1 / 5 \boldsymbol{c}^{*}$, orthorhombic, superspace group $\left.X m c m(00 \gamma) s 00\right]$ and supercell formalisms $\left[\mathrm{Hf}_{3} \mathrm{Ta}_{2} \mathrm{O}_{11}, Z=4, a=4.7834(13), b=5.1782(17), c=25.320(13) \AA\right.$, 
orthorhombic, space group Pbnm]. Transmission electron microscopy shows the microscopic structure from film-like aggregates down to atomic resolution. Cation ordering within the different available coordination environments is possible, but no significant hint at it is found within the limits of standard diffraction techniques. $\mathrm{Hf}_{3} \mathrm{Ta}_{2} \mathrm{O}_{11}$ is an unpredicted compound in the abovementioned oxide systems, in which stability ranges have been disputably fuzzy and established only by syntheses via solid-state routes so far.

\section{INTRODUCTION}

From the mid-2000s on, hafnium tantalum oxides have been deemed commercially attractive, mainly with respect to their use in semiconductor devices like metal-oxide semiconductor fieldeffect transistors (MOSFETs). ${ }^{1}$ Judging from the issuance of patents, interest peaked in 2012 and has since gradually shifted from products to processes. Sources show that these materials are far from going down the drain, while comprehension of their structure is still at the gates.

Of the 248 references available for hafnium tantalum oxides in the CAplus database, ${ }^{2} 200$ are patents that mostly deal with generic mixtures in the field $(\mathrm{Zr}, \mathrm{Hf}) \mathrm{O}_{2}-(\mathrm{Nb}, \mathrm{Ta})_{2} \mathrm{O}_{5}$, often including alumina, silica, and/or transition-metal dopants. Claimed applications besides semiconductors include superhard or high-temperature surface coatings and highly refractive or highly dielectric films. Materials are mainly produced via surface oxidation, chemical or physical vapor deposition. ${ }^{3}$ Usually, they remain structurally uncharacterized.

When it comes to this aspect, it is reasonable to consider compounds in the system $\left(\mathrm{Zr}, \mathrm{Hf} \mathrm{O}_{2}-\right.$ $(\mathrm{Nb}, \mathrm{Ta})_{2} \mathrm{O}_{5}$ together as they share basic features. The first compounds within (under omission of solid solutions and dopant-stabilized oxides) were reported by Roth and Coughanour in 1955: ${ }^{4}$ $\mathrm{Zr}_{6} \mathrm{Nb}_{2} \mathrm{O}_{17}$ and $\mathrm{Zr}_{6} \mathrm{Ta}_{2} \mathrm{O}_{17}$ crystallize in an orthorhombic cell with lattice parameters of ca. 4.9, 5.2, 
and $5.3 \AA$, which later proved typical for a part of the whole system. The isotypic hafnium analogues $\mathrm{Hf}_{6} \mathrm{Nb}_{2} \mathrm{O}_{17}$ and $\mathrm{Hf}_{6} \mathrm{Ta}_{2} \mathrm{O}_{17}$ were described in $1972 .{ }^{5}$ In the same year, Roth et al. discovered a whole range of compounds with $\alpha-\mathrm{PbO}_{2}$-homeotypic "superstructures" in the systems $\mathrm{ZrO}_{2}-\mathrm{Nb}_{2} \mathrm{O}_{5}$ and $\mathrm{ZrO}_{2}-\mathrm{Ta}_{2} \mathrm{O}_{5}$ having the common formula $\mathrm{Zr}_{n} M_{2} \mathrm{O}_{2 n+5}(M=\mathrm{Nb}, \mathrm{Ta} ; 5 \leq n \leq 8) .{ }^{6}$ Later, they also discovered and published shared crystal-structural construction principles. ${ }^{7}$ The system was then complemented with compounds reported as $\mathrm{Hf}_{5} \mathrm{Ta}_{2} \mathrm{O}_{15}$ and $\mathrm{Hf}_{7} \mathrm{Ta}_{2} \mathrm{O}_{19},{ }^{8}$ which were more likely the slightly off-stoichiometric $\mathrm{Hf}_{5.5} \mathrm{Ta}_{2} \mathrm{O}_{16}$ and $\mathrm{Hf}_{7.5} \mathrm{Ta}_{2} \mathrm{O}_{20 .}{ }^{6}$ With the advent of an understanding of modulated/composite structures and the development of the associated vocabulary, many of the hitherto discovered compounds were identified as commensurately modulated cases embedded in a broader field of incommensurately modulated structures. Their formulae range between $\mathrm{Zr}_{5.1} \mathrm{Nb}_{2} \mathrm{O}_{15.2}$ and $\mathrm{Zr}_{8.3} \mathrm{Nb}_{2} \mathrm{O}_{21.6},{ }^{9-11}$ with a later addition of $\mathrm{Zr}_{10} \mathrm{Nb}_{2} \mathrm{O}_{25}$, ${ }^{12}$ and show a common aspect: a relative richness in metal(IV) ions.

Structures rich in metal(V) ions are rarer: e.g., $\mathrm{ZrNb}_{24} \mathrm{O}_{62}{ }^{13}$ and $\mathrm{ZrNb}_{32} \mathrm{O}_{82}{ }^{14}$ have been reported with a distinctly different structure, polymorphism, and a somewhat unclear relationship to each other. All these compounds with their postulated solid-solution ranges constitute complex phase diagrams in the pseudo-binary systems $(\mathrm{Zr}, \mathrm{Hf}) \mathrm{O}_{2}-(\mathrm{Nb}, \mathrm{Ta})_{2} \mathrm{O}_{5}$ that have often been debated and revised in the past. ${ }^{15}$ Furthermore, the separation of thermodynamic and kinetic effects seems difficult for these high-melting materials. A dependency of the structure on the synthesis route (i.e., trapping of a metastable state) cannot be ruled out. New insight into these systems is also beneficial for a general understanding of related structures, e.g., homeotypic $\mathrm{Hf}: \mathrm{ZrTiO}_{4}$ with a closely related unit cell, ${ }^{16} \alpha-\mathrm{PbO}_{2}$-derived monoclinic $\mathrm{LiZnNb} 4 \mathrm{O}_{11.5},{ }^{17}$ or $\beta$ - $\mathrm{Ta}_{2} \mathrm{O}_{5}$ and the system $\mathrm{Ta}_{2} \mathrm{O}_{5}-\mathrm{WO}_{3}$ with shared fundamental structure principles. ${ }^{18-19}$

Herein, we report on the sol-gel synthesis and structure elucidation of the commensurately modulated phase $\mathrm{Hf}_{3} \mathrm{Ta}_{2} \mathrm{O}_{11}$, which is uncommonly metal(V)-rich for its structure, using electron, 
neutron, and X-ray diffraction. Results are presented using modern superspace and supercell descriptions. In the literature, a compound with this empirical formula has only been mentioned generically as a possible gate dielectric " $\mathrm{Hf}_{1-x} \mathrm{Ta}_{x} \mathrm{O}$ with $x=[\ldots]$ 40\%" (sic) without any structural characterization. ${ }^{1}$

\section{EXPERIMENTAL SECTION}

Synthesis: Amorphous hafnium-tantalum-oxide precursors were prepared using a modified Pechini route. ${ }^{20}$ Equivalent amounts of tantalum chloride (99.999\%, Sigma-Aldrich) and hafnium chloride (99.9\%, Sigma-Aldrich) were mixed and dissolved in ethanol (99.5\%, Acros Organics) containing citric acid ( $\geq 99.5 \%$, Sigma-Aldrich) in a twelvefold molar excess in relation to the cations. Ethylene glycol (99\%, Alfa Aesar) was added in a 17-fold molar excess. The resulting solution was heated to $473 \mathrm{~K}$ until a polymer formed. The gel was then calcined in a corundum crucible at $723 \mathrm{~K}$ for $40 \mathrm{~h}$ to yield a colorless powder, which was assessed as amorphous according to X-ray diffraction. In a next step, this amorphous precursor was placed in a corundum crucible in the center of a tube furnace. Under argon atmosphere, it was held at $1073 \mathrm{~K}$ for $3 \mathrm{~h}$ and finally allowed to cool to room temperature without further control to yield a fine colorless powder (typical scale: $c a .0 .5 \mathrm{~g}$ ).

Anal. Calcd. for pure $\mathrm{Hf}_{3} \mathrm{O}_{11} \mathrm{Ta} 2 \mathrm{H}, \mathrm{H}, 0.00 ; \mathrm{Hf}, 49.89 ; \mathrm{O}, 16.40$; Ta, 33.72. Found: $\mathrm{H}, 0.003(6)$; Hf, 38.5(13); O, 17.72(11); Ta, 44.8(16). Density (gas pycnometry): 9.02(10) $\mathrm{g} \mathrm{cm}^{-3}$.

Analytical methods: Oxygen and hydrogen content were determined using a "Leco EF-TC" 300 $\mathrm{N}_{2} / \mathrm{O}_{2}$ analyzer (hot-gas extraction) and a "Thermo Finnigan Flash EA 1112" analyzer, respectively. Volumetric mass density was measured using a "Quantachrome Multipycnometer" gas expansion pycnometer fed with helium (sample volume: $4.5 \mathrm{~cm}^{3}$ ). Hafnium and tantalum content were determined via X-ray fluorescence analysis using a wavelength-dispersive 
"PANalytical Axios" analyzer. The intensities of the Hf- $L_{\beta 1}(c a .9 .026 \mathrm{keV})$ and Ta- $L_{\beta 1}$ lines (ca. $9.355 \mathrm{keV}$ ) were selected using a (220)-oriented LiF crystal (no filter, collimator mask: $10 \mathrm{~mm}$, primary collimator distance: $150 \mu \mathrm{m}$, scintillation-detector range: $37-62^{\circ}$ ) and used with background correction and drift compensation. Mass absorption coefficients were calculated from the source-generated $\mathrm{Rh}$ lines. Intensities were calibrated against four standards prepared by mixing $\mathrm{HfO}_{2}\left(98.5 \%, w[\mathrm{Zr}]<1.5 \%\right.$, Alfa Aesar) and $\mathrm{Ta}_{2} \mathrm{O}_{5}(99.993 \%$ metal basis excluding $\mathrm{Nb}$, max. $50 \mathrm{ppm} \mathrm{Nb}$, Alfa Aesar) with molar Hf/Ta ratios of 0.8:1.2, 0.9:1.1, 1.0:1.0, and 1.1:0.9. All samples were measured as pressed wax pellets (Höchst-Wachs, $\mathrm{C}_{38} \mathrm{H}_{76} \mathrm{~N}_{2} \mathrm{O}_{2}$ ).

Transmission electron microscopy (TEM): The local chemical composition, microstructure, and electronic structure of the samples were investigated by analytical electron microscopy using a double $C_{\mathrm{S}}$-corrected scanning transmission-electron microscope "JEOL JEM-ARM200CF" operated at $200 \mathrm{kV}$ and equipped with a high-angle "Silicon Drift" EDX detector with a solid angle of up to $0.98 \mathrm{sr}$ from a detection area of $100 \mathrm{~mm}^{2}$. For electron microscopy, samples were prepared by drop deposition of powders dispersed in 2-propanol on a copper grid with a holey carbon support film.

Electron diffraction (ED): The data collection was performed on a "Philips CM 120" ( $\mathrm{LaB}_{6}$ cathode, $120 \mathrm{kV}$ ) equipped with a "NanoMEGAS DigiSTAR" precession unit, an "Olympus SIS Veleta" CCD camera $(2048 \times 2048$ pixels $)$. Diffraction data were collected using precession electron diffraction tomography. The crystallite was sequentially tilted in steps of $1^{\circ}$ between $-40^{\circ}$ and $39^{\circ}$ and, at every tilt step, a precession diffraction pattern was acquired using a precession angle of $0.5^{\circ}$. The diffraction patterns were collected in microdiffraction mode, i.e., the illuminated area was defined by the size of the beam and not by the selected area aperture.

The unit cell was searched and refined using JANA2006; $;{ }^{21}$ the type of the superspace group was established from systematic absences. After indexation, the data was integrated as $1 \times 1 \times 5$ 
supercell using an experimental version of the program PETS and transformed into (3+1)D superspace. The structure was solved with SUPERFLIP ${ }^{22}$ using a charge-flipping algorithm. Refinements were carried out using JANA2006. First, an incommensurately modulated model was established in kinematical approximation. After completion, it was converted to commensurate modulation (sections: $t=n / 5$ ) without any modification of the reflection data set. Further refinement was performed using the dynamical refinement method ${ }^{23}$ as implemented in the module Dyngo (refinement parameters: $R_{\mathrm{sg}}=0.75, g_{\max }=1.5,64$ integration steps). As soon as the model was nearly complete, individual per-frame tilt corrections were refined; tilt parameters were set to zero if physically meaningless tilt angles $\vartheta>0.4^{\circ}$ resulted. In the final stage, three frames had to be excluded from refinement because of severe mismeasurement (nearly oriented crystal). The resulting model includes refined individual scaling factors for each of the 77 frames, a global thickness parameter, positional and anisotropic displacement parameters for all atoms except O3 (non-positive-definite ADP matrix). For the cations, positional (up to second order, one parameter per direction) and ADP modulation (up to second order, two parameters per principal axis) were refined. Occupancies of the oxide ions were modelled using crenel functions of fixed length and position as derived from composition and symmetry. Positional modulation was modelled for O1 and $\mathrm{O} 2$ using Legendre polynomials of the first and second order (both with one parameter per direction), respectively.

X-ray diffraction (XRD): Measurement was carried out at ambient temperature on a "PANalytical X'Pert PRO MPD” diffractometer equipped with a "PIXcel” detector using nickelfiltered $\mathrm{Cu}-K_{\alpha}$ radiation $\left(\lambda_{1}=1.54056 \AA, \lambda_{2}=1.54439 \AA, I_{2} / I_{1}=0.5\right)$ in Bragg-Brentano $(\theta-\theta)$ geometry. Initial LeBail fits and following calculations were carried out using JANA2006. ${ }^{21}$ Peak profiles were fitted with a pseudo-Voigt function using the Thompson-Cox-Hastings approach (Gaussian parameters $U, V$, and $W$; Lorentzian parameter $X$ ). Asymmetry was corrected for using 
the Bérar-Baldinozzi method with four parameters. ${ }^{24}$ Displacement and transparency corrections were applied. The background was modelled using ten Legendre polynomials between 16 manually defined points. Only satellite reflections of first order were discernible and thus used in refinements. For subsequent Rietveld refinements, the final model from electron diffraction was imported. A scale factor and two parameters for roughness correction according to Pitschke, Hermann, and Mattern were introduced. ${ }^{25}$ A critical inspection of de-Wolff sections led to keeping only the occupancy modulation for the more weakly scattering oxide ions. Data allowed refining anisotropic displacement (without modulation) for the cation and isotropic displacement for $\mathrm{O}$. Isotropic displacement parameters for $\mathrm{O} 2$ and $\mathrm{O} 3$ were fixed at $U_{\text {iso }}=0.018 \AA^{2}$ to match $U_{\text {iso }}(\mathrm{O} 1)$ and $U_{\text {eq }}(\mathrm{Hfl} / \mathrm{Ta} 1)$.

Neutron diffraction (ND): Measurement was carried out at FRM II (Heinz Maier-Leibnitz Zentrum, Garching b. München) using the high-resolution powder diffractometer SPODI with Ge(551)-monochromated constant-wavelength (CW) radiation $(\lambda=1.54829 \AA)$ in Debye-Scherrer geometry. ${ }^{26}$ The compacted powder sample was mounted in a vanadium cylinder and exposed for ca. 7 h. Data were recorded with an array of 80 position-sensitive ${ }^{3} \mathrm{He}$ tubes $\left(2 \theta_{\max }=160^{\circ}\right.$, effective height: $300 \mathrm{~mm}$ ) and reduced using a variable-height algorithm as implemented in the in-house parser ${ }^{27}$ yielding a final range of $0.95^{\circ} \leq 2 \theta \leq 151.90^{\circ}$ with $\Delta(2 \theta)=0.05^{\circ}$. Initial LeBail fits and following calculations were carried out using JANA2006. ${ }^{21}$ Neutron data were analytically corrected for absorption (cylindrical sample) and stripped of the steep onset below $10^{\circ}$ and the noisy tail above $150^{\circ}$. Peak profiles were fitted with a pseudo-Voigt function using the ThompsonCox-Hastings approach (Gaussian parameters $U, V$, and $W$; Lorentzian parameters $X$ and $Y$ ). Asymmetry was corrected for using the Bérar-Baldinozzi method with two parameters. ${ }^{24}$ A zeroshift correction was applied. The background was modelled using 15 Legendre polynomials between 23 manually defined points. Satellite reflections up to second order were necessary to fit 
the pattern satisfactorily. For subsequent Rietveld refinement, the final model from electron diffraction was imported and a scale factor was introduced. A critical inspection of de-Wolff sections led to a reduction of positional modulation parameters to two (first order for $x$ and $y$ directions) for O2. Data allowed refining anisotropic displacement for the cation without modulation and isotropic displacement for the oxide ions.

Structure graphics were produced using Diamond 4.5. ${ }^{28}$ Results of calculations were visualized using OriginPro 2018. ${ }^{29}$ Bond-valence sums were calculated using VaList $4.0 .7^{30}$ and softBV $0.96 .^{31}$

\section{RESULTS AND DISCUSSION}

Preliminary Experiments. Starting from equimolar amounts of hafnium(IV) and tantalum(V) citrate, we tentatively assigned the resulting oxide the formula " $\mathrm{Hf}_{2} \mathrm{Ta}_{2} \mathrm{O}_{9}$ " at first. However, routine powder X-ray diffraction seemed to indicate a structure of the $\alpha-\mathrm{PbO}_{2}$ type (cf. Fig. S2). As the associated cation/anion ratio could only be realized in pure hafnia, for which this structure type would be unprecedented, we tried to locate the oxide ions via ND (scattering power more evenly distributed between cations and anions). To our surprise, the resulting powder diffraction pattern showed more reflections than assumed, which were, above all, severely size-broadened. TEM then set us on the right path, suggesting a modulated structure with a roughly fivefold supercell.

Crystal Structure from ED Tomography. We then tried to solve the structure from ED data. During selection of a suitable crystallite, we discovered ample particles that did not diffract electrons and, therefore, had to be considered amorphous. A data set was collected from an appropriate, albeit small, single crystallite (see Fig. 1). 


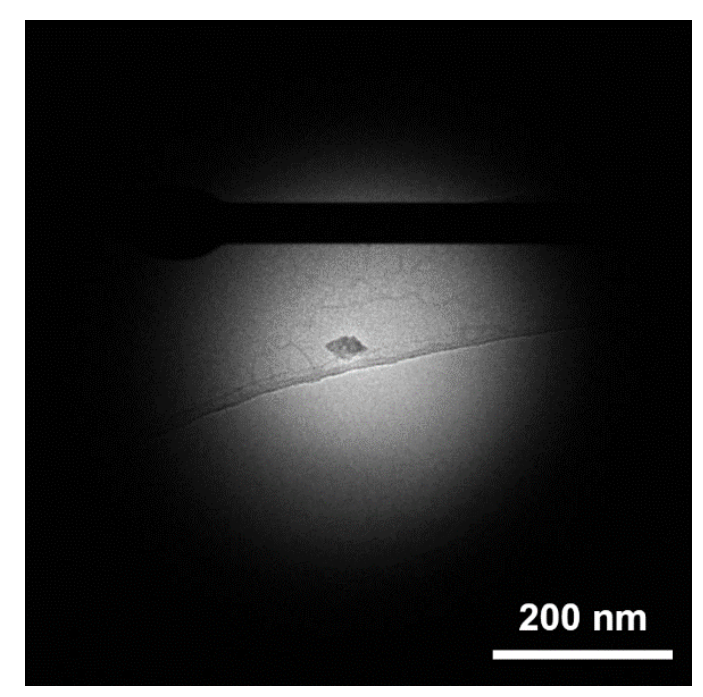

Figure 1. TEM image of the crystallite, from which the ED data set was acquired.

As the data were of rather high quality, they allowed solution and refinement of the modulated structure without major problems. In the case of commensurate modulation, there are two equivalent descriptions: the $(3+n) \mathrm{D}$ superspace model (see Table 1 for results) and the 3D supercell model (see Table 2). While the latter is easier to grasp (e.g., when it comes to interatomic distances) and readily processed by common software, relations between atomic parameters in a restricted space (i.e., if not all theoretically available parameters may be refined) can only be appropriately modelled in the former. For this reason, we refined in $(3+1) \mathrm{D}$ superspace and regard the resulting model as canonical but provide descriptions of ion positions, bond lengths, etc. in a $1 \times 1 \times 5$ supercell. To make the relationship between the two models more transparent, we assigned the atom numbers in the supercell in such a way that the first numeral refers to the generating atom in superspace and the second one counts the instances-e.g., the atoms $\mathrm{O} 11, \mathrm{O} 12$, and $\mathrm{O} 13$ in the supercell are derived from $\mathrm{O} 1$ in superspace ( $c f$. ellipsoid plots in Fig. S2). Analyzing the systematic absences, we chose a unit cell of the superspace-group type $X m c m(00 \gamma) s 00$ with the supercentering vector $(1 / 21 / 201 / 2)$ over the standard $C m c m(10 \gamma) s 00$, meaning there is an additional 
lattice point at the $C$ base but with the modulation functions shifted by half a period. This results in the space-group type Pbnm instead of the standard Pnma when transforming into the supercell. Another non-standard setting $A m m a(\alpha 10) 0 s 0$ of the same superspace-group type has been chosen explicitly for $\mathrm{Zr}_{6} \mathrm{Nb}_{2} \mathrm{O}_{17}{ }^{11}$ and $\mathrm{Zr}_{10} \mathrm{Nb}_{2} \mathrm{O}_{25}$, ${ }^{12}$ as well as implicitly for the incommensurately modulated structures of compounds in the field between $\mathrm{Zr}_{5.1} \mathrm{Nb}_{2} \mathrm{O}_{15.2}$ and $\mathrm{Zr}_{8.3} \mathrm{Nb}_{2} \mathrm{O}_{21.6 .}{ }^{10}$

Table 1. Crystallographic Data for $\mathrm{Hf}_{3} \mathrm{Ta}_{2} \mathrm{O}_{11}$ (Superspace Model)

\begin{tabular}{|c|c|c|c|}
\hline & Electrons & Neutrons $(\mathrm{CW})$ & X-rays \\
\hline Chemical formula & \multicolumn{3}{|c|}{$\mathrm{Hf}_{1.2} \mathrm{Ta}_{0.8} \mathrm{O}_{4.4}$} \\
\hline$M / \mathrm{g} \mathrm{mol}^{-1}$ & \multicolumn{3}{|c|}{429.3} \\
\hline$T / \mathrm{K}$ & $98.46(10)$ & 293 & 298 \\
\hline$\lambda / \AA$ & 0.0335 & 1.54829 & $1.54056,1.54439$ \\
\hline Crystal system & \multicolumn{3}{|c|}{ orthorhombic } \\
\hline Superspace group & \multicolumn{3}{|c|}{$X m c m(00 \gamma) s 00$ (No. 63.4) } \\
\hline$a / \AA$ & $4.7834(13)$ & $4.8816(3)$ & $4.8775(4)$ \\
\hline$b / \AA$ & $5.1782(17)$ & $5.2758(3)$ & $5.2746(5)$ \\
\hline$c / \AA$ & $5.064(3)$ & $5.1639(3)$ & $5.1604(5)$ \\
\hline$q$ & \multicolumn{3}{|c|}{$\left(\begin{array}{lll}0 & 0 & 1 / 5\end{array}\right)$} \\
\hline$V / \AA^{3}$ & $125.43(8)$ & $132.994(15)$ & $132.76(2)$ \\
\hline$Z$ & \multicolumn{3}{|c|}{2} \\
\hline$D_{\text {calcd }} / \mathrm{g} \mathrm{cm}^{-3}$ & 11.3675 & 10.7214 & 10.7401 \\
\hline$\mu / \mathrm{cm}^{-1}$ & - & 0.183 & 143.622 \\
\hline$R\left(F_{\mathrm{o}}\right)\left[\mathrm{all} / \mathrm{obs}^{\mathrm{a}}\right]$ & $0.1054 / 0.0592$ & $0.0180 / 0.0176$ & $0.0232 / 0.0231$ \\
\hline$w R\left(F_{\mathrm{o}}\right)^{\mathrm{b}}\left[\mathrm{all} / \mathrm{obs}^{\mathrm{a}}\right]$ & $0.1168 / 0.1085$ & $0.0234 / 0.0233$ & $0.0421 / 0.0420$ \\
\hline$R_{\mathrm{p}}$ & - & 0.0134 & 0.0093 \\
\hline
\end{tabular}




\begin{tabular}{|l|l|l|l|}
\hline$R_{\mathrm{wp}}^{\mathrm{b}}$ & - & 0.0164 & 0.0125 \\
\hline$S=\sqrt{\chi^{2}}$ & 2.23 & 1.55 & 3.72 \\
\hline
\end{tabular}

${ }^{\mathrm{a}} I>3 \sigma(I)$.

${ }^{\mathrm{b}} w=1 /\left[\sigma^{2}\left(F_{\mathrm{o}}\right)+0.0009 F_{\mathrm{o}}^{2}\right]$ for electrons, $w=1 /\left[\sigma^{2}(I)+(0.01 I)^{2}\right]$ for neutrons and X-rays.

Table 2. Unit-Cell Data for the Supercell Model (ED)

\begin{tabular}{|l|l|}
\hline Chemical formula & $\mathrm{Hf}_{3} \mathrm{Ta}_{2} \mathrm{O}_{11}$ \\
\hline$M / \mathrm{g} \mathrm{mol}^{-1}$ & 1073.4 \\
\hline Space group & Pbnm (No. 62) \\
\hline$a / \AA$ & $4.7834(13)$ \\
\hline$b / \AA$ & $5.1782(17)$ \\
\hline$c / \AA$ & $25.320(13)$ \\
\hline$V / \AA$ & $627.2(4)$ \\
\hline$Z$ & 4 \\
\hline
\end{tabular}

The crystal structure features three different coordination polyhedra around the cations (see Fig. 2a, also Fig. S3): a distorted octahedron (coordination number [CN]: 6), a distorted pentagonal bipyramid or capped trigonal prism (CN: 7), and a distorted bicapped trigonal prism (CN: 8). Slabs of identical polyhedra are stacked along the $c$ axis, giving rise to the coordination-number sequence $6-7-8-7-6$ that repeats once per supercell. If considered bonding, two longer contacts (cf. Table S1, italics) would lead to a capped octahedron $(\mathrm{CN}: 6+1)$ and another bicapped trigonal prism $(\mathrm{CN}$ : $7+1)$. Because of their distinct length, however, we do not regard them as bonds. 

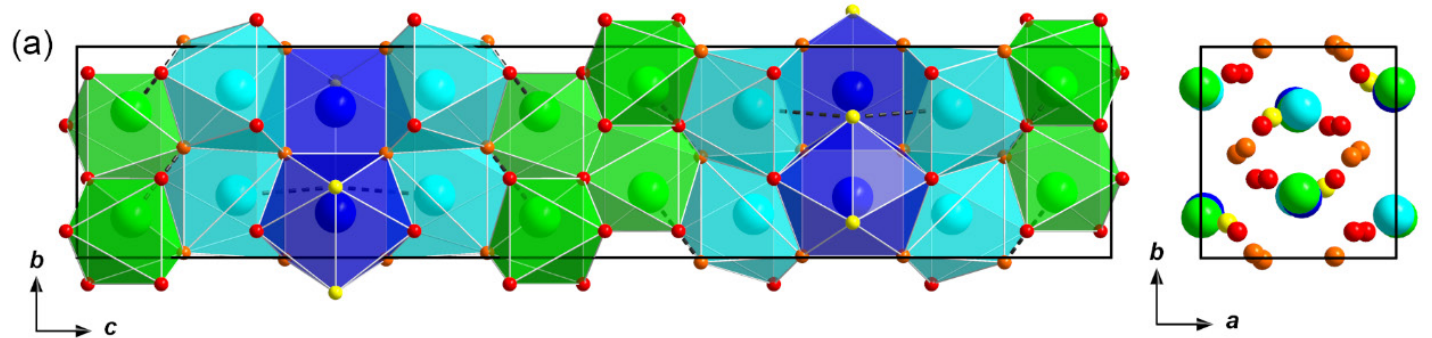

(b)
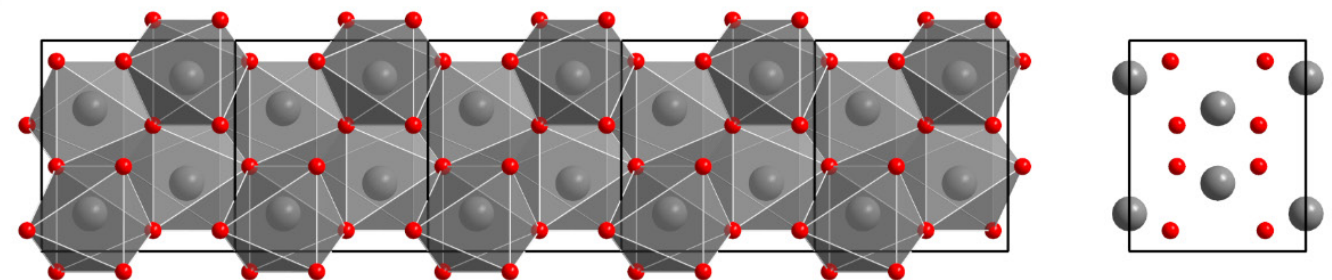

Hf/Ta1 (CN: 6) Hf/Ta1 (CN: 7) Hf/Ta1 (CN: 8) $\mathrm{Pb} 1$ 01 02 03

Figure 2. Crystal structures of (a) $\mathrm{Hf}_{3} \mathrm{Ta}_{2} \mathrm{O}_{11}$ (supercell model from $\mathrm{ED}$ ) and (b) $\alpha-\mathrm{PbO}_{2}$ (quintuple unit cell $)^{32}$ in two different views. Atoms with arbitrary radii, non-bonding contacts as grey dashed lines, unit cells in black.

Real-Space Structure. To complement reciprocal space information with real-space images of the atomic arrangement, high-resolution scanning transmission electron microscopy (STEM) imaging was performed. The overview bright-field STEM micrograph in Fig. 3a shows that the sample consists mostly of thin sheets of percolated nanocrystalline particles that are randomly oriented. (This is confirmed by the occurrence of rings in the ED pattern of the selected area displayed as an inset in Fig. 3a.) High-angle annular dark-field (HAADF) imaging of a nanocrystallite reveals a modulation of atomic rows along [001], which manifests as stripes and satellites in the corresponding Fourier transform (see Fig. 3b with inset). Atomic resolution HAADF (see Fig. 3c) shows the cations as bright dots, whereas the oxide ions occupy the dark spaces in between. Rows of equidistant cations form blocks of five that are alternating in a zigzag-like arrangement. The blocks are shifted by roughly $1 / 6 b$ along [010] relative to each other, as is expected for an $\alpha-\mathrm{PbO}_{2}$-homeotype structure. Each block represents the 6-7-8-7-6 coordination motif of half a supercell with a somewhat larger Hf11/Ta11 $\cdots$ Hfl 1/Ta1 1 distance to the next block. 
This gives rise to a supercell with $c \approx 25 \AA$-five times larger than the cell in superspace description, which contains only two rows.

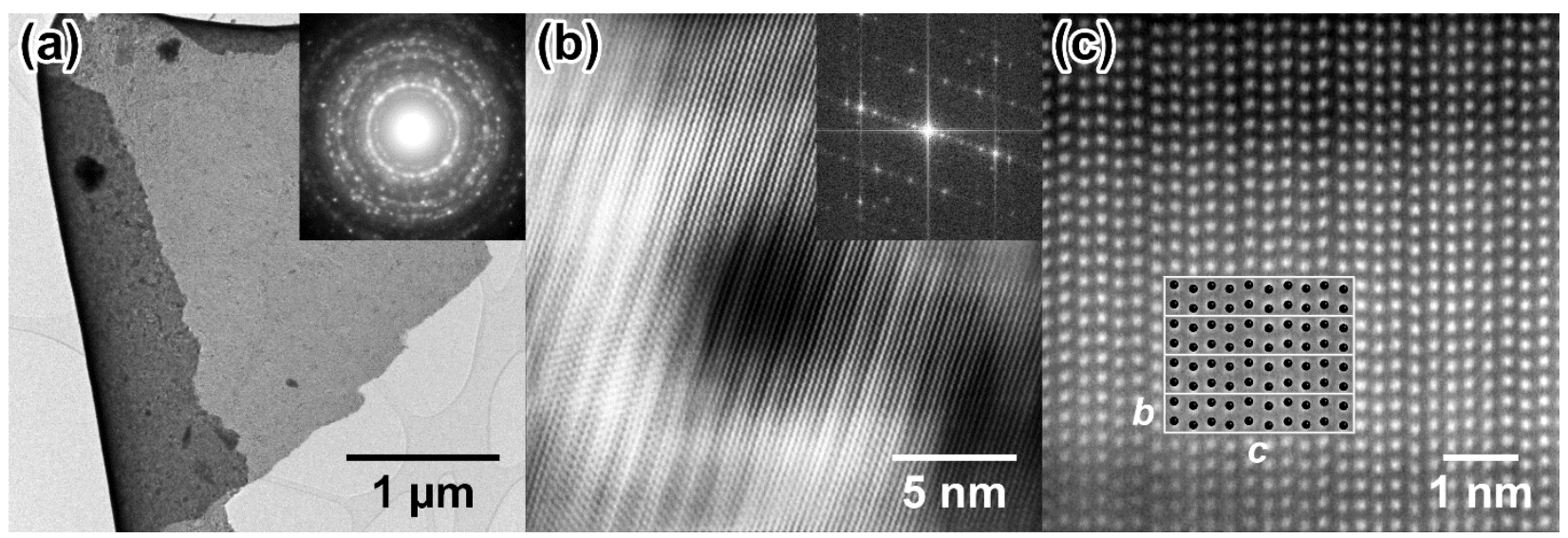

Figure 3. (a) Bright-field STEM image of a polycrystalline sheet with corresponding selected-area diffraction pattern as inset; (b) HAADF image recorded along the [110] zone axis with Fouriertransform inset, which reveals satellites corresponding to the supercell; (c) HAADF image in [100] projection showing the arrangement of cation rows with overlay of four supercells (cation positions in black, unit cells in white).

Structural Relationships. A glance at the structure of $\alpha-\mathrm{PbO}_{2}$ (see Fig. 2b) reveals a close relationship to that of $\mathrm{Hf}_{3} \mathrm{Ta}_{2} \mathrm{O}_{11}$. The cation positions are very similar and the pairs of slabs with octahedral coordination ( $c f$. Fig. 2, green) may be interpreted as sections from the $\alpha-\mathrm{PbO}_{2}$ structure. The polyhedra with eightfold coordination, on the other hand ( $c f$. Fig. 2, dark blue), resemble those present in the $\mathrm{YF}_{3}$ type, as has also been described for $\mathrm{Zr}_{x-2} \mathrm{Nb}_{2} \mathrm{O}_{2 x+1}(7 \lesssim x \lesssim 12) .{ }^{33}$ The polyhedra with sevenfold coordination ( $c f$. Fig. 2, turquoise), have an intermediate configuration to connect the aforementioned slabs. This structure fulfills the bauplan for the homologuous series $M_{m} \mathrm{O}_{2 m+1}$ ( $M$ : metal, $m$ : multiplicity) as proposed by Galy and Roth and is a realization of the hitherto missing 
member with $m=5{ }^{7}$ In principle, the series is generated by adding an $\alpha-\mathrm{PbO}_{2}$-like slab (n.b., the authors classified them as sevenfold coordinated) for each increase in $m$.

The average structure of $\mathrm{Hf}_{3} \mathrm{Ta}_{2} \mathrm{O}_{11}$ is - and that is common for all members of the aforementioned series - a stuffed derivative of the $\alpha-\mathrm{PbO}_{2}$ type (see Fig. 4). A closer look reveals that the oxide positions in $\alpha-\mathrm{PbO}_{2}$ are also realized approximately in $\mathrm{Hf}_{3} \mathrm{Ta}_{2} \mathrm{O}_{11}$, but many more are present. The space-group type of the average structure is $\mathrm{Cmcm}$, which also describes the symmetry of the cation substructure in the $\alpha-\mathrm{PbO}_{2}$ type. The space-group type of the complete $\alpha$ $\mathrm{PbO}_{2}$ structure, $\mathrm{Pbcn}$, is a maximal klassengleiche subgroup $(k 2)$ of $\mathrm{Cmcm}$. The anions account for symmetry lowering (i.e., loss of centering, mirror planes, and the generated additional screw axes and inversion centers). Pbnm, the space-group type of the fivefold supercell structure, is a klassengleiche subgroup of $\mathrm{Cmcm}$ of index $10(\mathrm{k} 2 \circ i 5)$. For further details on this, see Figure S8.

(a)

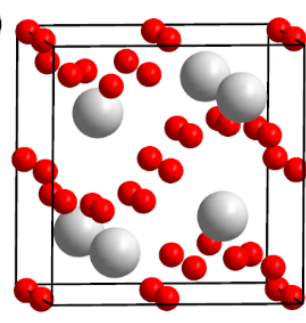

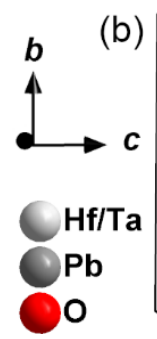

(b)

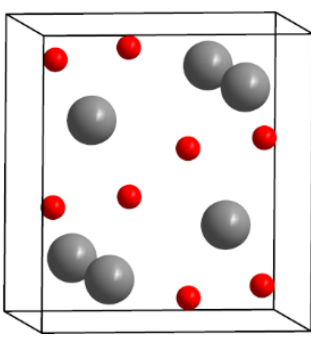

Figure 4. Average crystal structure of (a) $\mathrm{Hf}_{3} \mathrm{Ta}_{2} \mathrm{O}_{11}$ and (b) $\alpha-\mathrm{PbO}_{2}$ (atoms with arbitrary radii, unit cell in black).

Powder X-Ray and Neutron Diffraction: The structural model derived from ED was used to interpret the X-ray and neutron powder-diffraction patterns previously acquired. In both cases, the model was adjusted to reflect the information content of the method before Rietveld refinement. The results accounted for all features of the diffraction patterns (see Figs. 5 and 6, Table 1). No phase transformation was detected between ED cryogenic and XRD/ND ambient temperature ( $c a$. 
100-300 K). We found no indication of an additional phase contributing to Bragg diffraction. In both cases, reflection broadening due to the small crystallite size was considerable - in agreement with the findings from electron microscopy.

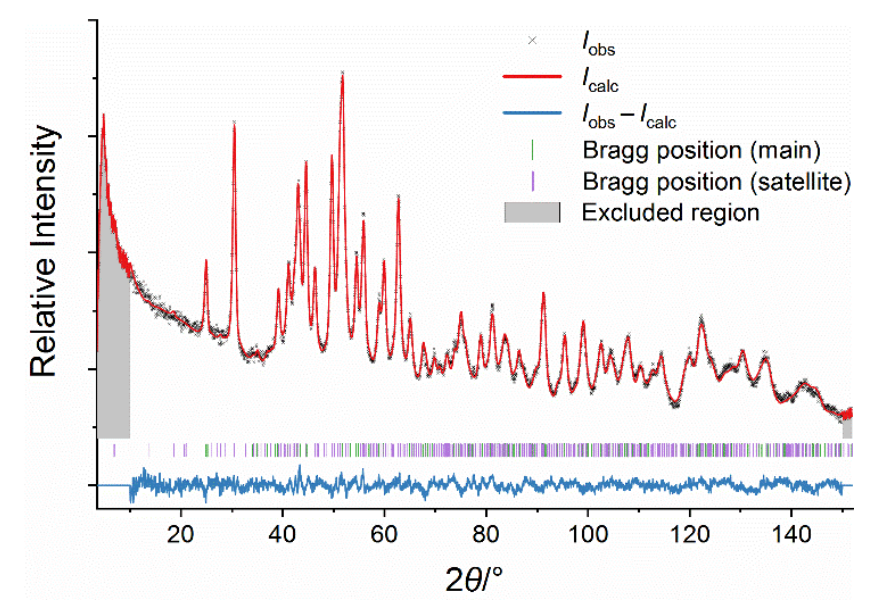

Figure 5. Neutron diffraction patterns $(\lambda=1.54829 \AA)$ of $\mathrm{Hf}_{3} \mathrm{Ta}_{2} \mathrm{O}_{11}$ at ambient temperature.

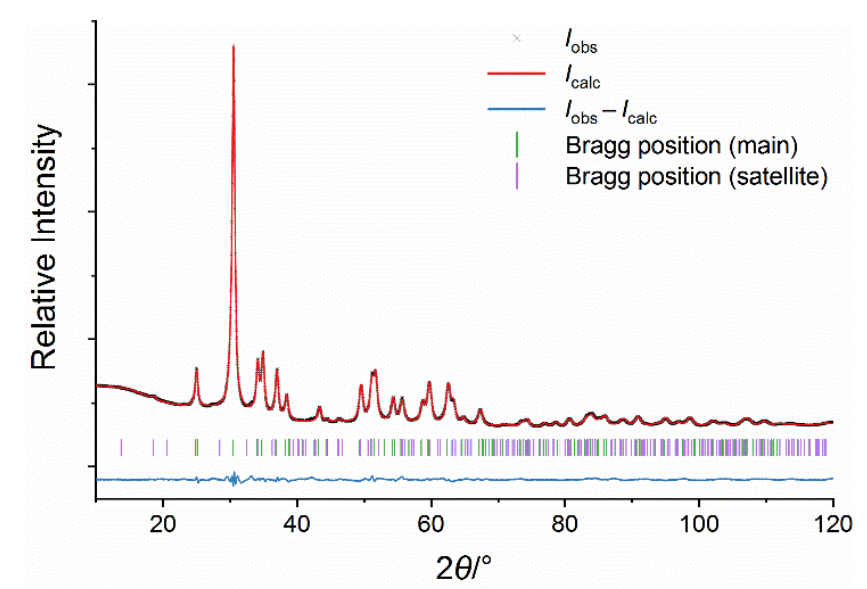

Figure 6. X-ray diffraction patterns of $\mathrm{Hf}_{3} \mathrm{Ta}_{2} \mathrm{O}_{11}$ at ambient temperature. Only $\mathrm{Cu}-K_{\alpha 1}$ Bragg positions reported for clarity. 
The X-ray diffraction pattern was recorded over a long time for a high signal-to-noise ratio. In comparison with the refinement of an $\alpha-\mathrm{PbO}_{2}$-type model (cf. Fig. S2), the final fit (see Fig. 6 and Table 2) accounts also for the clearly discernible satellite reflections of the first order and shows a drop of roughly one third in all residuals.

Cation Disorder. As the structure provides three crystal-chemically different cation positions (in the supercell model), cation ordering is at least possible. To judge the suitability of the positions, we calculated bond-valence sums (BVS) using two algorithms: a classical and the softnesssensitive approach (see Table 3). For the former, BVS have been calculated considering and neglecting the additional non-bonding contacts. Unfortunately, the global instability index (GII) cannot be used to assess model quality because of algorithmic problems with handling cation disorder. A position is considered suitable if the associated BVS matches the oxidation state of the ion. All positions are overbonded for hafnium(IV) and rather fit to host tantalum(V), as the mismatches are smaller for the latter. The smallest mismatch for hafnium(IV) is, however, found at Hf13, making it the preferred candidate for hosting. Based on the calculations from VaList (CN: 6, 8, and 7), ideal occupation ratios for the positions would be Hf11/Ta11=18:82, Hf12/Ta12 = 4:96, Hf13/Ta13 = 45:55 (not constrained by composition). Hereby, a preference of tantalum(V) for Ta12 is predicted, whereas the softness-sensitive algorithm sees it more evenly distributed over Ta11 and Ta12.

Table 3. BVS and their Mismatch ${ }^{\mathrm{a}}$ for the Cation Positions According to Different Algorithms

\begin{tabular}{|l|l|c|l|l|}
\hline Ion & \multicolumn{2}{|l|}{ VaList } & \multicolumn{2}{|l|}{ softBV $^{\mathbf{l}}$} \\
\hline & BVS & Mismatch & BVS & Mismatch \\
\hline $\mathrm{Hf}^{\mathrm{V}} 11$ & $5.135[7] / 4.856[6]$ & $1.135 / 0.856$ & $4.9240[9]$ & 0.9240 \\
\hline $\mathrm{Ta}^{\mathrm{V}} 11$ & $5.092[7] / 4.815[6]$ & $0.092 /-0.185$ & $5.3429[9]$ & 0.3429 \\
\hline
\end{tabular}




\begin{tabular}{|l|l|l|l|l|}
\hline $\mathrm{Hf}^{\mathrm{IV}} 12$ & $4.995[8]$ & 0.995 & $4.9850[12]$ & 0.9850 \\
\hline $\mathrm{Ta}^{\mathrm{V}} 12$ & $4.958[8]$ & -0.042 & $5.4191[12]$ & 0.4191 \\
\hline $\mathrm{Hf}^{\mathrm{IV}} 13$ & $4.759[8] / 4.571[7]$ & $0.759 / 0.571$ & $4.7215[10]$ & 0.7215 \\
\hline $\mathrm{Ta}^{\mathrm{V}} 13$ & $4.721[8] / 4.534[7]$ & $-0.279 /-0.466$ & $5.1344[10]$ & 0.1344 \\
\hline
\end{tabular}

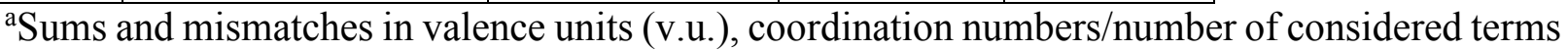
in brackets.

${ }^{b}$ Based on softness-sensitive bond valences. ${ }^{34}$

Experimentally, cation order can only be detected with $\mathrm{ND}\left(b_{\mathrm{c}}[\mathrm{Hf}]=7.7 \mathrm{fm}, b_{\mathrm{c}}[\mathrm{Ta}]=6.91 \mathrm{fm}\right.$, $\left.\delta b_{\mathrm{c}} \approx 10 \%\right),{ }^{35}$ as the isoelectronic tantalum(V) and hafnium(IV) ions are indiscernible via ED and XRD. A test refinement of cation occupation in the supercell model (constrained to full occupation at each position) showed an insignificant decrease only in $w R\left(F_{\mathrm{o}}\right)$ and $w R_{\mathrm{B}}$ with a maximal improvement of 0.0012 . Occupation ratios refined to Ta11/Hf11 $=0.66(11): 0.34(11)$, Ta12/Hf12 = 0.28(12):0.22(12), and Ta13/Hf13 =0.03(16):0.97(16) exhibiting large standard uncertainties. The resulting formula is $\mathrm{Hf}_{1.223} \mathrm{Ta}_{0.777} \mathrm{O}_{4.4}$; attempted refinements with constrained composition did not converge. At first glance, the occupation of Hf13 indeed approaches unity and Ta11 seems to be preferred by tantalum. The difference to an even distribution $(0.4: 0.6,0.2: 0.3$, 0.4:0.6), however, is statistically insignificant. Hence, refinement does not contradict the assumptions from BVS analysis but is indecisive. A possible correlation of the modulation with cation ordering was assessed via inspection of difference de-Wolff sections of cation scatteringlength desity. ${ }^{36}$ Whereas they show slight changes along the modulation dimension, an adapted model with crenel-like occupation modulation (equaling a supercell model with Ta11, Hf12, and Hf13) performed slightly worse in terms of all $R$ values (by ca. 0.1 percentage point) and did not allow to refine a displacement modulation, individual displacement parameters, or individual position-modulation parameters for the cations. 
To assess the general possibility of solving this very problem via ND, we simulated two neutron diffraction patterns with profile parameters similar to the one of the given sample and diffractometer: one with complete cation disorder, one with hafnium at $\mathrm{Hf} 13$ and statistical cation distribution over the remaining positions. Judging from the intensity difference relative to the completely disordered model and the measurement-only standard uncertainty (see Fig. 7), merely a handful of reflections with $2 \theta<40^{\circ}$ are even diagnostic, the foremost being below the first main reflection at $c a \cdot 25^{\circ}$. Their difference relative to the local intensity in the fully disordered model is ample (see Table 4). However, the difference relative to the average intensity of the whole diffraction pattern is very low, meaning it would easily be passed over in refinement due to model uncertainty.

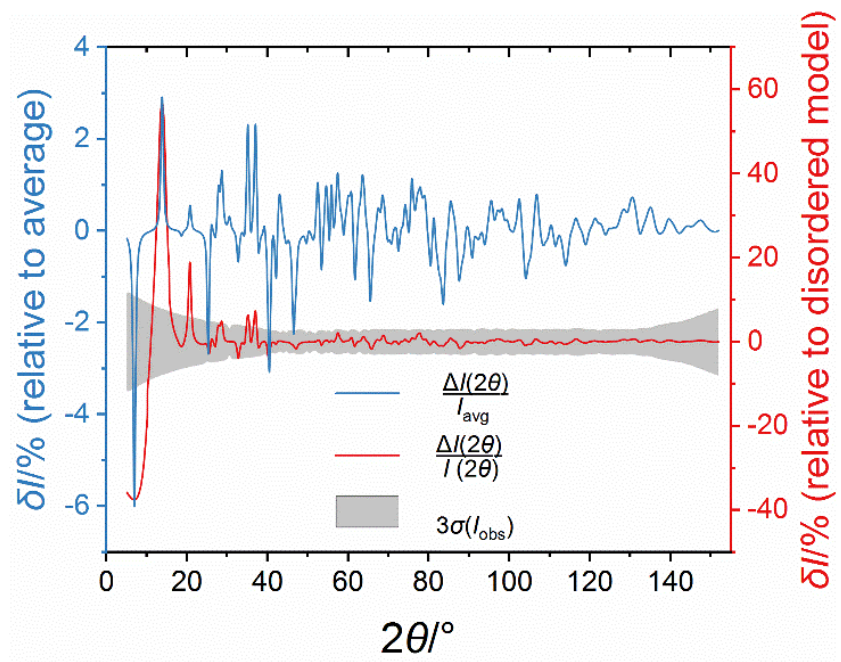

Figure 7. Relative differences between simulated neutron diffraction patterns for statistical cation disorder and most probable partial disorder (only Hf at position Hf13/Ta13). Confidence interval for $99.73 \%$ (grey background) derived from the given measurement. 
Table 4. Diagnostic Reflections for Partial Cation Ordering

\begin{tabular}{|l|l|l|l|l|}
\hline $2 \theta /{ }^{\circ}$ & $\begin{array}{l}\text { Bragg indices } \\
\text { (superspace) }\end{array}$ & $\begin{array}{l}\text { Bragg indices } \\
\text { (supercell) }\end{array}$ & $\frac{\Delta I(2 \theta)}{I(2 \theta)}$ & $\frac{\Delta I(2 \theta)}{I_{\text {avg }}}$ \\
\hline $6.9^{\mathrm{a}}$ & $(0002)$ & $(002)$ & $-37 \%$ & $-6.0 \%$ \\
\hline 13.8 & $(001 \overline{1})$ & $(004)$ & $+57 \%$ & $+2.9 \%$ \\
\hline 20.7 & $(0011)$ & $(006)$ & $+19 \%$ & $+0.6 \%$ \\
\hline 21.0 & $(101 \overline{2})$ & $(103)$ & & \\
\hline
\end{tabular}

${ }^{\mathrm{a} C u t}$ out due to the steep high background.

Sample purity. Whereas, from diffraction, we conclude that $\mathrm{Hf}_{3} \mathrm{Ta}_{2} \mathrm{O}_{11}$ is the only crystalline phase in the sample, synthesis from roughly equimolar metal amounts ( $c f$. X-ray fluorescence analysis) and the predicted non-volatility of any oxide by-products preclude it from being phasepure. We assume that the excess tantalum(V) takes the form of amorphous oxides, possibly with a minor admixture of hafnium(IV). Elemental analysis corroborates this assumption: the sample contains a surplus of oxygen, which means there has to be at least one additional phase with a higher average oxidation state of the metals. The absence of hydrogen rules out the formation of hydrates as a possible source. Pycnometry gave a distinctly lower density than expected from crystallography (average from ND and XRD: $10.73 \mathrm{~g} \mathrm{~cm}^{-3}$ ), thus hinting at a low-density by-phase. An amorphous tantalum(V)-rich oxide would be a suitable candidate as densities given in the literature for amorphous or low-temperature $\beta$ - $\mathrm{Ta}_{2} \mathrm{O}_{5}$ range between 7.93 and $8.58 \mathrm{~g} \mathrm{~cm}^{-3} .37$

\section{CONCLUSIONS}

We synthesized a new phase with the composition $\mathrm{Hf}_{3} \mathrm{Ta}_{2} \mathrm{O}_{11}$ and a hitherto unknown structure via a modified Pechini route. The areas it and its analogues occupy in the pseudo-binary phase 
diagrams of $(\mathrm{Hf}, \mathrm{Zr}) \mathrm{O}_{2}-(\mathrm{Ta}, \mathrm{Nb})_{2} \mathrm{O}_{5}$ were previously reported as two-phase and/or solid-solution regions containing mixtures of $(\mathrm{Hf}, \mathrm{Zr})_{6}(\mathrm{Nb}, \mathrm{Ta})_{2} \mathrm{O}_{17}$ and $(\mathrm{Hf}, \mathrm{Zr})(\mathrm{Nb}, \mathrm{Ta})_{24} \mathrm{O}_{62}$ or $\left(\mathrm{Nb}, \mathrm{Ta}_{2} \mathrm{O}_{5}{ }^{4,}, 6,8\right.$, ${ }^{38}$ It is the most metal(V)-rich compound crystallizing within its family of modulated structures with orthorhombic cells. We assume that the sol-gel synthesis instead of the reported solid-state approaches made this compound accessible for us. Yet, it is unknown if the substance is stable or metastable with regard to possible mixtures of other oxides (see above). As the composition does not correspond to the metal amounts used in synthesis, we assume that the product is a mixture of the new phase and an amorphous fraction. This is in agreement with pycnometry, elemental analysis, and findings from TEM.

The crystal structure of $\mathrm{Hf}_{3} \mathrm{Ta}_{2} \mathrm{O}_{11}$ is a member of a family of modulated structures characterized by the formulae $(\mathrm{Hf}, \mathrm{Zr})_{x-2}(\mathrm{Ta}, \mathrm{Nb})_{2} \mathrm{O}_{2 x+1}$. As such, it complements those of $\mathrm{Hf}_{5} \mathrm{Ta}_{2} \mathrm{O}_{15} / \mathrm{Hf}_{5.5} \mathrm{Ta}_{2} \mathrm{O}_{16}$, $\mathrm{Hf}_{6} \mathrm{Ta}_{2} \mathrm{O}_{17} / \mathrm{Hf}_{6.5} \mathrm{Ta}_{2} \mathrm{O}_{18}$, and $\mathrm{Hf}_{7} \mathrm{Ta}_{2} \mathrm{O}_{19} / \mathrm{Hf}_{7.5} \mathrm{Ta}_{2} \mathrm{O}_{20}$ (see Introduction) differing from it and from one another mostly in the length of the modulation vector. Literature reports on their common construction principles, but not all of them have been mathematically formalized. It is often cumbersome or even impossible to translate such findings into contemporary models. Herein, we presented a state-of-the-art description that is compatible with modern software and database formats. The synthesis with $r(\mathrm{Hf} / \mathrm{Ta}) \approx 1: 1$ shows that an incommensurately modulated field (like between $\mathrm{Zr}_{5.1} \mathrm{Nb}_{2} \mathrm{O}_{15.2}$ and $\mathrm{Zr}_{8.3} \mathrm{Nb}_{2} \mathrm{O}_{21.6}$ ) either does not exist between hypothetical " $\mathrm{Hf}_{2} \mathrm{Ta}_{2} \mathrm{O}_{9}$ " and $\mathrm{Hf}_{3} \mathrm{Ta}_{2} \mathrm{O}_{11}$ or is not accessible via our sol-gel route.

The origin of structural modulation may be a relief of the severe overbonding that is especially pronounced for hafnium(IV) ions in an $\alpha-\mathrm{PbO}_{2}$-derived coordination environment. A correlation with cation order, especially in light of the dependence of the modulation length on the cation ratio, would then be conceivable. Unfortunately, our investigations were indecisive with regard to possible cation order. Because we did not find any evidence for ordering, we stuck to a disordered 
model. To settle this matter finally, neutron diffraction with an exceptionally high signal-to-noise ratio at $2 \theta<25^{\circ}$ would be needed to overcome diagnostic uncertainty.

\section{ASSOCIATED CONTENT}

Supporting Information. The Supporting Information is available free of charge on the ACS Publications website at DOI:

Additional figures and tables: diffraction pattern with fit of an $\alpha-\mathrm{PbO}_{2}$-type model, ellipsoid plots, stereoview of crystal structure, bond lengths, de-Wolff sections, and Bärnighausen tree (PDF).

Accession Codes. CCDC 1861844-1861847 contain the supplementary crystallographic data for this paper. These data can be obtained free of charge from The Cambridge Crystallographic Data Centre via www.ccdc.cam.ac.uk/structures.

Copyright Notice. The TOC graphic is a derivative work of "P-Channel MOSFET 20V 24A -

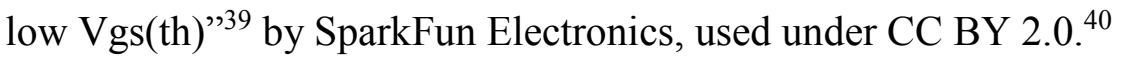

\section{AUTHOR INFORMATION}

\section{Corresponding Author}

*E-mail: dennis.wiedemann@chem.tu-berlin.de.

\section{Author Contributions}

The manuscript was written through contributions of all authors. All authors have given approval to the final version of the manuscript. 


\section{Funding Sources}

Authors D.W., T.L, and M.L. received funding from Deutsche Forschungsgemeinschaft (SPP 1613, LE 781/13-2).

\section{ACKNOWLEDGMENT}

This work is in part based upon experiments performed at the SPODI instrument operated by FRM II at the Heinz Maier-Leibnitz Zentrum (MLZ), Garching, Germany. Financial support by the DFG is gratefully acknowledged. The authors thank Dr. Steven Orthmann and Ms. Susanne Hoffmann for support performing pycnometry and Dr. Stefan Berendts (all TU Berlin) for conducting oxygen and X-ray fluorescence analyses.

\section{REFERENCES}

1. Zhang, M. H.; Rhee, S. J.; Kang, C. Y.; Choi, C. H.; Akbar, M. S.; Krishnan, S. A.; Lee, T.; Ok, I. J.; Zhu, F.; Kim, H. S.; Lee, J. C., Improved electrical and material characteristics of HfTaO gate dielectrics with high crystallization temperature. Appl. Phys. Lett. 2005, 87 (23), 232901-1-232901-3.

2. SciFinder: Chemical Abstracts Service: Columbus, OH, 2018; search for multi-component formulae; https://scifinder.cas.org (accessed Jul 20, 2018).

3. Baum, T. H.; Xu, C.; Paw, W.; Hendrix, B. C.; Roeder, J. F.; Wang, Z. Source Reagent Composition for CVD Formation of $\mathrm{Zr} / \mathrm{Hf}$ Doped Gate Dielectric and High Dielectric Constant Metal Oxide Thin Films and Method of Using Same. US 20020132048, 2002/09/19, 2002. 
4. Roth, R. S.; Coughanour, L. W., Phase Equilibrium Relations in the Systems Titania-Niobia and Zirconia-Niobia. J. Res. Natl. Bur. Stand. (U. S.) 1955, 55 (4), 209-213.

5. Chan, F. L.; Johnson, G. G., X-Ray Diffraction Study of New Hafnium Compounds. Dev. Appl. Spectrosc. 1972, 10, 307-329.

6. Roth, R. S.; Waring, J. L.; Brower, W. S.; Parker, H. S., Superstructure of the Orthorhombic $\mathrm{Nb}_{2} \mathrm{O}_{5} \cdot 6 \mathrm{ZrO}_{2}$ Type Phase(s) in the $\mathrm{Nb}_{2} \mathrm{O}_{5}-\mathrm{ZrO}_{2}$ and $\mathrm{Ta}_{2} \mathrm{O}_{5}-\mathrm{ZrO}_{2}$ Systems. NBS Spec. Publ. (U. S.) 1972, 364, 183-195.

7. Galy, J.; Roth, R. S., The Crystal Structure of $\mathrm{Nb}_{2} \mathrm{Zr}_{6} \mathrm{O}_{17}$. J. Solid State Chem. 1973, 7 (3), $277-285$.

8. Spiridonov, F. M.; Mulenkova, M. N.; Tsirel'nikov, V. I.; Komissarova, L. N., Intermediate Phases in the $\mathrm{HfO}_{2}-\mathrm{Ta}_{2} \mathrm{O}_{5}$ System. Russ. J. Inorg. Chem. 1981, 26 (6), 922-923.

9. Thompson, J. G.; Withers, R. L.; Sellar, J.; Barlow, P. J.; Hyde, B. G., Incommensurate Composite Modulated $\mathrm{Nb}_{2} \mathrm{Zr}_{x-2} \mathrm{O}_{2 x+1}: x=7.1-10.3$. J. Solid State Chem. 1990, 88 (2), 465-475.

10. Withers, R. L.; Thompson, J. G.; Hyde, B. G., A Modulation-Wave Approach to the Structural Description of the $\mathrm{Nb}_{2} \mathrm{Zr}_{x-2} \mathrm{O}_{2 x+1}(x=7.1-10.3)$ Solid-Solution Field. Acta Crystallogr., Sect. B: Struct. Sci. 1991, 47 (2), 166-174.

11. Schmid, S.; Thompson, J. G.; Withers, R. L.; Petříček, V.; Ishizawa, N.; Kishimoto, S., ReRefinement of Composite Modulated $\mathrm{Nb}_{2} \mathrm{Zr}_{x-2} \mathrm{O}_{2 x+1}(x=8)$ Using Synchrotron Radiation Data. Acta Crystallogr., Sect. B: Struct. Sci. 1997, 53 (6), 851-860. 
12. Fütterer, K.; Schmid, S.; Thompson, J. G.; Withers, R. L.; Ishizawa, N.; Kishimoto, S., The Structure Refinement of Compositely Modulated $\mathrm{Nb}_{2} \mathrm{Zr}_{x-2} \mathrm{O}_{2 x+1}(x=12)$. Acta Crystallogr., Sect. B: Struct. Sci. 1995, 51 (5), 688-697.

13. Allpress, J. G.; Roth, R. S., Structural Studies by Electron Microscopy: Polymorphism of $\mathrm{ZrO}_{2} \cdot 12 \mathrm{Nb}_{2} \mathrm{O}_{5}$. J. Solid State Chem. 1970, 2 (3), 366-376.

14. Stephenson, N. C.; Beale, J. P.; Craig, D. C., The Structure and Intergrowth of the Polymorphic Forms of $\mathrm{ZrO}_{2} \cdot 16 \mathrm{Nb}_{2} \mathrm{O}_{5}$. NBS Spec. Publ. (U. S.) 1972, 364, 165-182.

15. Mestres, L.; Martínez-Sarrión, M. L.; Castaño, O.; Fernández-Urbán, J., Phase Diagram at Low Temperature of the System $\mathrm{ZrO}_{2} / \mathrm{Nb}_{2} \mathrm{O}_{5}$. Z. Anorg. Allg. Chem. 2001, 627 (2), 294-298.

16. Yamamoto, A.; Yamada, T.; Ikawa, H.; Fukunaga, O.; Tanaka, K.; Marumo, F., Modulated Structure of Zirconium Titanate. Acta Crystallogr., Sect. C: Cryst. Struct. Commun. 1991, 47 (8), $1588-1591$.

17. Morozov, V. A.; Arakcheeva, A. V.; Konovalova, V. V.; Pattison, P.; Chapuis, G.; Lebedev, O. I.; Fomichev, V. V.; Van Tendeloo, G., LiZnNb${ }_{4} \mathrm{O}_{11.5}$ : A novel oxygen deficient compound in the Nb-rich part of the $\mathrm{Li}_{2} \mathrm{O}-\mathrm{ZnO}-\mathrm{Nb}_{2} \mathrm{O}_{5}$ system. J. Solid State Chem. 2010, 183 (2), 408-418.

18. Stephenson, N. C.; Roth, R. S., Structural Systematics in the Binary System $\mathrm{Ta}_{2} \mathrm{O}_{5}-\mathrm{WO}_{3}$. V. The Structure of the Low-Temperature Form of Tantalum Oxide $L-\mathrm{Ta}_{2} \mathrm{O}_{5}$. Acta Crystallogr., Sect. B: Struct. Crystallogr. Cryst. Chem. 1971, 27 (5), 1037-1044.

19. Williams, J. M.; Tilley, R. J. D.; Harburn, G.; Williams, R. P., Interpretation of L-Ta $\mathrm{T}_{2} \mathrm{O}_{5^{-}}$ type Diffraction Patterns in Terms of a One-dimensional Shift Lattice. J. Chem. Soc., Faraday Trans. 1992, 88 (3), 325-331. 
20. Okubo, T.; Kakihana, M., Low temperature synthesis of $\mathrm{Y}_{3} \mathrm{NbO}_{7}$ by polymerizable complex method: Utilization of a methanol-citric acid solution of $\mathrm{NbCl}_{5}$ as a novel niobium precursor. J. Alloys Compd. 1997, 256 (1), 151-154.

21. Petříček, V.; Dušek, M.; Palatinus, L., Crystallographic Computing System JANA2006: General Features. Z. Kristallogr. - Cryst. Mater. 2014, 229 (5), 345-352.

22. Palatinus, L.; Chapuis, G., SUPERFLIP - a computer program for the solution of crystal structures by charge flipping in arbitrary dimensions. J. Appl. Crystallogr. 2007, 40 (4), 786-790.

23. Palatinus, L.; Petříček, V.; Corrêa, C. A., Structure refinement using precession electron diffraction tomography and dynamical diffraction: theory and implementation. Acta Crystallogr., Sect. A: Found. Adv. 2015, 71 (2), 235-244.

24. Bérar, J.-F.; Baldinozzi, G., Modeling of Line-Shape Asymmetry in Powder Diffraction. $J$. Appl. Crystallogr. 1993, 26 (1), 128-129.

25. Pitschke, W.; Hermann, H.; Mattern, N., The influence of surface roughness on diffracted X-ray intensities in Bragg-Brentano geometry and its effect on the structure determination by means of Rietveld analysis. Powder Diffr. 1993, 8 (2), 74-83.

26. Hoelzel, M.; Senyshyn, A.; Dolotko, O., SPODI: High resolution powder diffractometer. $J$. Large-Scale Res. Facil. 2015, 1, A5.

27. Hoelzel, M.; Senyshyn, A.; Juenke, N.; Boysen, H.; Schmahl, W.; Fuess, H., HighResolution Neutron Powder Diffractometer SPODI at Research Reactor FRM II. Nucl. Instrum. Methods Phys. Res., Sect. A 2012, 667, 32-37. 
28. Brandenburg, K. Diamond: Crystal and Molecular Structure Visualization, version 4.5; Crystal Impact - H. Putz \& K. Brandenburg GbR: Bonn, Germany, 2018.

29. OriginLab OriginPro: Data Analysis and Graphing Software, version 2018; OriginLab Corp.: Northampton, USA, 2018.

30. Wills, A. S. VaList: Bond Valence Calculations and Listing, version 4.0.7; University College London: London, UK, 2011.

31. Adams, S. softBV: Softness Sensitive Bond Valence, version 0.96; Georg-AugustUniversität Göttingen: Göttingen, Germany, 2004.

32. Filatov, S.; Bendeliani, N.; Albert, B.; Kopf, J.; Dyuzeva, T.; Lityagina, L., High-pressure synthesis of $\alpha-\mathrm{PbO}_{2}$ and its crystal structure at 293, 203, and $113 \mathrm{~K}$ from single crystal diffraction data. Solid State Sci. 2005, 7 (11), 1363-1368.

33. Sellar, J. R., Disorder, superlattice canting and chiral domains in zirconia-niobia ceramic alloys. Acta Crystallogr., Sect. A: Found. Crystallogr. 1999, 55 (2 Part 1), 220-227.

34. Adams, S., Relationship between bond valence and bond softness of alkali halides and chalcogenides. Acta Crystallogr., Sect. B: Struct. Sci. 2001, 57 (3), 278-287.

35. Sears, V. F., Neutron scattering lengths and cross sections. Neutron News 1992, 3 (3), 2637.

36. Morozov, V. A.; Arakcheeva, A. V.; Chapuis, G.; Guiblin, N.; Rossell, M. D.; Van Tendeloo, G., $\mathrm{KNd}\left(\mathrm{MoO}_{4}\right)_{2}$ : A New Incommensurate Modulated Structure in the Scheelite Family. Chem. Mater. 2006, 18 (17), 4075-4082. 
37. Reisman, A.; Holtzberg, F., $\mathrm{Nb}_{2} \mathrm{O}_{5}$ and $\mathrm{Ta}_{2} \mathrm{O}_{5}$ Structure and Physical Properties. In High Temperature Oxides: Oxides of Rare Earths, Titanium, Zirconium, Hafnium, Niobium and Tantalum, Alper, A. M., Ed. Academic Press: New York, NY, 1970; pp 217-257.

38. Zheng, C.; West, A. R., Phase Equilibria and Electrical Properties in the System $\mathrm{ZrO}_{2}-$ $\mathrm{La}_{2} \mathrm{O}_{3}-\mathrm{Nb}_{2} \mathrm{O}_{5}$. Br. Ceram. Trans. J. 1990, 89, 138-141.

39. Flickr. P-Channel MOSFET 20V 24A - low Vgs(th). https://www.flickr.com/photos/sparkfun/14187398264 (accessed Jul 31, 2018).

40. Creative Commons. Attribution 2.0 Generic $-\quad$ CC $\quad$ BY 2.0 . https://creativecommons.org/licenses/by/2.0/ (accessed Jul 31, 2018). 